\title{
Knowledge of non-communicable diseases and practices related to healthy lifestyles among adolescents, in state schools of a selected educational division in Sri Lanka
}

\author{
A. U. Gamage ${ }^{1 *}$ and P. L. Jayawardana ${ }^{2}$
}

\begin{abstract}
Background: Behaviors established during the adolescence have life-long consequences to the onset of noncommunicable diseases (NCDs) in later life. Therefore, it is essential to understand adolescents' knowledge and practices with the intention of developing preventive programs focusing on this age group. The objective of the study was to assess knowledge about selected NCDs, and lifestyle choices among school students aged 1719 years in state schools of the Maharagama Educational Division, Sri Lanka.
\end{abstract}

Methods: A descriptive, cross-sectional study was conducted among students aged 17-19 years attending state schools in Maharagama Education Division. A total of 634 students were selected from 9 schools conducting Advance Level classes. Stratified sampling was done based on stream of study and the number needed from each stratum was decided according to probability proportionate to size which was followed by cluster sampling within the strata to select the classes included.

Data were collected using a self-administered-questionnaire on socio-demographic characteristics and economic status; lifestyle-related practices; knowledge on Non-Communicable -Diseases. Logistic regression was used to assess the associations.

Results: Proportion students with good overall knowledge was 43\%( $n=272)$. Forty-three percent $(n=275)$ consumed a healthy diet, and $20 \%(n=129)$ engaged in adequate physical activity $3 \%(n=18)$ of students were current smokers and $12 \%(n=73)$ current alcohol users $12 \%(n=73)$.

Overall "good" knowledge about NCDs was associated with being a science stream student(OR $=3.3 ; 95 \% \mathrm{Cl}: 2.1-5.2)$. Healthy diet was associated with female sex $(\mathrm{OR}=2.1 ; 95 \% \mathrm{Cl}: 1.5-3.0)$, and adequate physical activity with male sex $(\mathrm{OR}=2.1 ; 95 \% \mathrm{Cl}: 1.4-3.2)$, non-science-stream (OR $=2.1 ; 95 \% \mathrm{Cl}: 1.2-3.7)$ and upper socio economic status $(\mathrm{OR}=2.0$; 95\%Cl:1.3-3.0). Non-smoking was associated with overall good knowledge $(\mathrm{OR}=4.1 ; 95 \% \mathrm{Cl}: 1.2-13.7)$ and female sex $(\mathrm{OR}=0 ; 95 \% \mathrm{Cl}: 1.5$-infinity). Abstinence from alcohol was associated with being a female (OR $=6.9 ; 95 \% \mathrm{Cl}: 3.4-13.9)$, and with mother and fathers' education level of $>$ General-Certificate of Examinations Ordinary Level (GCE O/L) (OR = 2.9; 95\%Cl:1.1-8.4 and $\mathrm{OR}=3.5 ; 95 \% \mathrm{Cl}: 1.1-11.2$ respectively).

Conclusion: Knowledge about NCDs and healthy lifestyle-practices were poor among school students aged 1719 years. Lack of knowledge about healthy and unhealthy behaviors highlights the importance of carrying out regular surveillance for NCD risk factors, and initiating programs for the prevention of NCDs amongst adolescents.

Keywords: Non-communicable disease, Knowledge, Lifestyle practices, Prevention, Adolescents

\footnotetext{
* Correspondence: anujigamage@gmail.com

${ }^{1}$ Consultant Community Physician, Ministry of Health, 385, Ven. Baddegama

Wimalawansa Thero Mawatha, Colombo 10, Sri Lanka

Full list of author information is available at the end of the article
} 


\section{Background}

Non-communicable diseases (NCDs) are diseases that are not transmissible from one person to another. [1] Commonly existing NCDs include hypertension, diabetes mellitus, cardiovascular diseases (coronary heart disease and stroke), cancers, injuries and chronic respiratory disease. Among the main contributing factors are older age and unhealthy lifestyle-related behaviours, hence the term "lifestyle-related diseases." A general improvement of socio-economic factors within Sri Lanka and the resulting increase in life expectancy, has contributed to an increase in the prevalence of NCDs. [2, 3].

Adolescents are classified as individuals between the ages of 10 to 19 years. [4] In Sri Lanka, 19.7\% of the population (3.7 million people) are adolescents; a majority of whom (72.9\%) are school goers. [5] It is a wellknown fact that most lifestyle-related risk factors for NCDs are laid down during this period. [5, 6] This calls for action to prevent the establishment of risk factors from the early years of life; by arming adolescents with adequate knowledge about chronic diseases and healthy preventive practices. Evidence on the current knowledge and lifestyle-related practices of adolescents would immensely help both the health and education sectors with planning and implementation of much needed programs for school children. Educating students at the school level is considered to have a significant impact on the prevention of NCDs. [5, 7].

The present study aims to determine the level of knowledge about selected NCDs and the level of engagement in healthy behaviours, among school students aged 17-19 years in state schools of the Maharagama Educational Division in the district of Colombo, Sri Lanka. Specifically, it will assess knowledge levels on coronary heart disease, diabetes mellitus, hypertension, cerebrovascular disease, and cancers, as well as knowledge about the relevant primary preventive measures for these diseases including the lifestyle measures, which have been adopted to prevent the above NCDs.

\section{Methods}

\section{Participants}

A descriptive cross-sectional study was conducted among students aged 17 to 19 years, in GeneralCertificate of Examinations Advanced Level class, attending state schools in the Maharagama education division, of the Colombo district, Sri Lanka. The study was conducted in the Western Province (one of nine provinces in the country), which is further divided into three districts (Colombo, Gampaha, and Kalutara). The Education Department has divided each district into education zones, with Maharagama education division one of the four such zones within the Colombo district. Of the 1359 national and provincial schools in the Western
Province, 406 are located in the Colombo district. Among the 47,179 students enrolled for the GeneralCertificate of Examinations Advanced Level (GCE A/L classes) (year 12 and 13) country-wide in 2010, 13,301 were in Arts, 18,955 in Commerce, and 14,923 in Science streams. [8].

In total, the number of schools conducting GCE A/L classes in the Maharagama division was nine, with 1044 year-12 and 13 students distributed within the three streams of study (Arts, Commerce, and Science).

Based on the formula proposed by Lwanga, Lemeshow, [9] the initial sample size calculated was 384, having considered a proportion with adequate knowledge and practices for each as $50 \%$. This sample size was subsequently inflated with a design effect set at 1.5 and addition of a non-response rate of $5 \%$. The resulting sample size, of 605 , was then further inflated to obtain integer division with the cluster size set at 25 (the minimum number of students available in the classes selected for the study). Thus, the final sample size computed was 625 with a total of $25(625 / 25)$ clusters selected from the nine schools.

The required number of classes from each stratum was calculated by applying probability proportion to the size of the student population in each stratum, which was $22 \%, 32 \%$ and $45 \%$ in the Science, Arts, and Commerce streams, respectively. Thus the number of classes required were selected randomly resulting in eight Science: eleven Arts, and 16 Commerce classes, respectively. Despite the calculated sample size, all students in a selected class (the number of students in a given class ranged from 25 to 35 ) were included due to ethical requirements, with the final number of students recruited to the study and included in the analysis as 634 .

\section{Study instrument}

A self-administered-questionnaire was used to gather data from recruited participants. The questionnaire consisted of four components: socio-demographic characteristics and socio-economic status; lifestyle-related practices; knowledge on NCDs, and sources of information. The designing of the latter was based on the Pan American Health Organization (PAHO) NCD surveillance toolkit, [10] and the STEP-wise-approach-to-Surveillance (STEPS) of NCD risk factor questionnaire. [11] The socio-economic status component was based on a questionnaire to assess socio-economic index, resulting in a composite score. [12] The Questionnaire is provided in Additional file 1.

When preparing the questionnaire, the use of technical terms was kept to a minimum to retain clarity, particularly for the benefit of Commerce and Arts students who took part in the study. Questionnaires were provided anonymously, to maximize accuracy and reliability 
concerning the responses obtained. The questionnaire was developed in Sinhala language and pre-tested among $15 \mathrm{GCE} \mathrm{A} / \mathrm{L}$ students representing all three-study streams from a different educational division, to avoid the influence of testing effect.

Students' anthropometric measurements were collected by research staff and recorded in a data extraction sheet. Weight (using a digital weighing scale) and height (using a microtoise steel tape) were obtained using standard techniques, rounding to the nearest $100 \mathrm{~g}$ for weight, and $0.5 \mathrm{~cm}$ for height.

\section{Data analysis}

\section{Analysis of practices}

Assessment of the level of physical activity was based upon those who gave a positive response to being engaged in some form of moderate to vigorous physical activity. They were further classified as those with adequate/inadequate physical activity based on the following criteria: time duration of exercise $\geq 60 \mathrm{~min}$ on a daily basis. [13] The physical activity was considered adequate only if both criteria were fulfilled.

A student was considered to have healthy dietary habits if the following criteria were met: Consuming 1 ) home prepared breakfast for $\geq 5$ days/week; 2) non-fast food for breakfast for $\geq 5$ days/ week; 3 ) fruits $\geq 5$ days/ week; 4) $\geq 5$ servings/day of vegetables and green leaves 5) consuming fruit juice $\geq 5$ days/week; 6) carbonated drinks infrequently $(<2$ days/week $)$, and 7$)$ nonconsumption of additional salt (in comparison to their other family members). Each fulfilled criterion was given one point, with a maximum possible score of seven. Those who obtained a score $\geq 5$ were considered as having healthy dietary habits. The dietary questionnaire used for the current study was not validated previously.

A smoker was defined as one who smokes currently. Those who had previously (but not currently), or never smoked were considered as non-smokers. A student who was currently consuming alcohol was considered as 'consuming alcohol, 'and those who had previously (but not currently), or never consumed were considered as "not consuming alcohol."

\section{Analysis of knowledge}

This section consisted of 39 questions related to student's knowledge about NCDs and their risk factors. Correct answers were given a score of 1 and incorrect answers given 0 . The total possible score ranged from 0 to 216 and was expressed as a percentage the total possible score. Components and assignment of the score for knowledge is provided in Additional file 2. A cut-off level $\geq 60 \%$, the median value of the individual percentage scores, was selected as an indicator of "good" knowledge.

\section{Socio-economic status}

Socio-economic status was based upon a composite score, developed and validated for the Sri Lankan setting, comprising separate scores of eight individual variables (father's education status, mother's education status, father's occupation status, mother's occupation status, material used for the floor, availability of latrine facility, source of drinking water, possessions of items by the family members). [12] The sample was divided into quintiles based on the individual composite score computed, and assigned accordingly to five socio-economic classes. For the analysis of associations, the top two (1st and 2nd quintiles of higher social classes) and lower three quintiles (3rd-5th quintiles of lower social classes) were amalgamated.

\section{Body mass index}

Body mass index (BMI) was calculated for each student using his or her weight and height measurement. The cutoff values for BMI were based on World Health Organization (WHO) reference values for adolescents. [14, 15].

We used SPSS [16] data analysis and statistical software to report data as the means \pm SD and medians for continuous variables and proportions, then percentages for categorical values. Bivariate analyses were conducted using chi-square test. The level considered significant was a probability $(\mathrm{p})$ value of less than 0.05 . The factors, which had a $p$-value of $\leq 0.25$, and the biologically plausible ones, despite having a $p$ value of $>0.25$ were included in a multiple logistic regression analysis. List wise deletion method was used for missing data. Associations were expressed as odds ratios (OR) and their respective 95\% confidence intervals (95\% CI).

\section{Results}

The computed sample size was 625 , and the number of students in the selected classes was 696. Of these, 62 were absent, giving a non-response rate of $8.9 \%$. The total number of students included in the study was 634; all of whom were included in the analyses. The distribution of students by study stream was $41.2 \%(n=243)$ from Arts, $38.2 \%(n=261)$ from Commerce and $20.5 \%$ $(n=130)$ from Science.

\section{Demographic and socioeconomic characteristics}

The mean age of the sample was 18.4 $(\mathrm{SD}=0.38)$ years, $45.3 \%(n=287)$ of which were male students. 626 (98.7\%) were Sinhalese. Tamil and Moors were each $0.5 \%(n=3)$ and Burghers 0.3\% $(n=2)$ [Table 1]. The highest proportion of fathers (22.9\%: $n=145)$ and mothers $(29 \% ; n=184)$ had passed the General Certificate of Education; Ordinary Level (GCE O/L) examination. Concerning the socio-economic status (SES), the 
Table 1 Frequency distribution of demographic and socioeconomic. Characteristics of the advanced level students

\begin{tabular}{|c|c|c|c|}
\hline Variable $^{a}$ & Females & Males & Total (Row) \\
\hline \multirow[t]{2}{*}{ Total } & $347(54.7 \%)$ & $287(45.3 \%)$ & $634(100 \%)$ \\
\hline & n (\%) & n (\%) & n (\%) \\
\hline \multicolumn{4}{|l|}{ Ethnicity } \\
\hline Sinhalese & $341(98.2)$ & $285(99.3)$ & $626(98.7)$ \\
\hline Tamil & $3(0.9)$ & $0(0)$ & $3(0.5)$ \\
\hline Moors & $3(0.9)$ & $0(0)$ & $3(0.5)$ \\
\hline Burger & $0(0)$ & $2(0.7)$ & $2(0.3)$ \\
\hline \multicolumn{4}{|l|}{ Father's level of education } \\
\hline No schooling & $2(0.6)$ & $0(0)$ & $2(0.3)$ \\
\hline Grade 1-5 & $15(4.3)$ & $6(2.1)$ & $21(3.3)$ \\
\hline Grade 6-10 & $63(18.2)$ & $41(14.3)$ & $104(16.4)$ \\
\hline Passed GCE O/L ${ }^{\mathrm{a}}$ & $72(20.7)$ & $73(25.4)$ & $145(22.9)$ \\
\hline Up to GCE A/L ${ }^{\mathrm{b}}$ & $56(16.2)$ & $46(16.0)$ & $102(16.1)$ \\
\hline Passed GCE A/L & $74(21.3)$ & $63(22.0)$ & $137(21.6)$ \\
\hline University/Professional degree & $16(4.6)$ & $28(9.8)$ & $44(6.9)$ \\
\hline Not known/ Missing & $49(14.1)$ & $30(10.4)$ & $79(12.5)$ \\
\hline \multicolumn{4}{|l|}{ Mother's level of education } \\
\hline No schooling & $2(0.6)$ & $1(0.3)$ & $3(0.5)$ \\
\hline Grade 1-5 & $14(4.0)$ & $9(3.1)$ & $23(3.6)$ \\
\hline Grade 6-10 & $54(15.6)$ & 39 (13.6) & $93(14.7)$ \\
\hline Passed GCE O/L & $107(30.8)$ & $77(26.9)$ & $184(29.0)$ \\
\hline Up to GCE A/L & $63(18.2)$ & $58(20.2)$ & $121(19.1)$ \\
\hline Passed GCE A/L & $77(22.2)$ & $67(23.3)$ & $144(22.7)$ \\
\hline University/Professional degree & $4(1.2)$ & $13(4.5)$ & $17(2.7)$ \\
\hline Not known/ Missing & $26(7.4)$ & $23(8.1)$ & $49(7.7)$ \\
\hline \multicolumn{4}{|l|}{ Socioeconomic status } \\
\hline First Quintile-poorest & $73(21.0)$ & $29(10.1)$ & $102(16.1)$ \\
\hline Second Quintile & $43(12.4)$ & $43(15.0)$ & 86 (13.6) \\
\hline Third Quintile & $51(14.7)$ & $52(18.2)$ & $103(16.2)$ \\
\hline Fourth Quintile & $52(15.0)$ & $51(17.8)$ & $103(16.2)$ \\
\hline Fifth quintile-richest & $59(17.0)$ & $65(22.5)$ & $124(19.6)$ \\
\hline Not known/ Missing & 69 (19.9) & $47(16.4)$ & $116(18.3)$ \\
\hline Mean age (SD) years & $17.9(0.56)$ & $18.9(0.5)$ & $18.4(0.38)$ \\
\hline
\end{tabular}

${ }^{\mathrm{a}} \mathrm{General}$ Certificate of Education; Ordinary Level Examination

${ }^{\mathrm{b}}$ General Certificate of Education; Advanced Level Examination

highest proportion (19.6\%: $n=124$ ) belonged to the richest quintile (5th quintile).

\section{Practices}

The proportion of students involved in adequate physical activity among those engaged in physical activity was $31.8 \%(129 / 406)$ and among all students was $20.3 \%$ $(129 / 634)$. The majority of all students $(73.3 \%: n=465)$ consumed breakfast prepared at home for $\geq 5$ days/week, and $60.9 \%(n=386)$ consumed healthy food (rice or rice-flour based food) for breakfast most of the week ( $\geq 5$ days/week). However, 8.1\% $(n=52)$ reported consuming bread or wheat flour based products for $\geq 5$ days/week (Table 2 ).

A majority of all students $(92.7 \% ; n=588)$ did not consume more salt than their family members. $65 \%(n=413)$ consumed more fresh-fruit drinks than artificial ones $(31.5 \% ; n=200)$. Only $24.1 \%(n=153)$ reported consuming fruits for $\geq 5$ days, and $31.7 \%$ $(n=201)$ reported $\geq 5$ servings of vegetables/day. Based on the cut-off value of a score of $\geq 5,52.2 \%(n=181)$ of females and $32.8 \%(n=94)$ of males had healthy dietary habits.

The proportion of current smokers was $2.8 \%(n=18)$, and all were males. Among them, three (0.5\%) students were daily smokers. The mean number of cigarettes smoked per day was $2.1(\mathrm{SD}=1.3)$. The mean age at commencement of smoking was $16(\mathrm{SD}=0.8)$ years.

The proportion of students currently consuming alcohol was $11.5 \%(n=73)$, and among them, $83.5 \%(61 / 73)$ were males. 89 (25.6\%) males and 24 (6.7\%) females reported consuming alcohol previously. The mean age at commencement of consuming alcohol was 16.1 (SD =1.3) years.

According to the computed BMI values, 49.8\% $(n=316)$ of the students were underweight. More females were underweight $(n=183 ; 52.7 \%)$ than males $(n=133 ; 46.3 \%)$. The proportion of overweight was $6.6 \%$ $(n=42)$ and obesity $4.6 \%(n=29)$. Obesity and overweight was significantly more prevalent in males $(n=43 ; 15 \%)$ than females $(n=28 ; 8.1 \%) ;(p<0.005)$.

\section{Level of knowledge}

Forty-three percent $(42.9 \% ; n=272)$ of students obtained a score of $\geq 60 \%$, (mean; $119.7(\mathrm{SD}=31.0)$, median;124, IQR;99.7to141) for overall knowledge.

When individual subject areas were considered, a higher proportion of students had "good" knowledge on coronary artery disease (56.3\%; $n=356$ ) (mean;13.4 (SD = 4.7), median;14, IQR; 11 to 17$)$, diet (74.9\%; $n=475)$ (mean;25.9 (SD = 6.6), median;27, IQR;22 to 31 ) and physical activity (56.6\%; $n=359$ ) (mean;6.8 $(\mathrm{SD}=2.9)$, median;7,IQR; 5 to 9) [Table 3].

Of the student who scored $\geq 60 \%$, majority were females $(n=148$; 54.4\%), $265(97.4 \%)$ were Sinhalese students. A majority $(n=85,65.4 \%)$ of the science students scored $\geq 60 \%$. Considering parent's education level and "good overall knowledge," 205 (80.4\%) student's whose father's had an education of $\geq \mathrm{GCE} \mathrm{O} / \mathrm{L}$ obtained a score of $\geq 60 \%$. Similarly, Majority of the students $(n=209$; $80.0 \%$ ) of who's mothers had an education of $\geq$ GCE O/ $\mathrm{L}$ obtained a score of $\geq 60 \%$. Hundred and thirty-eight students (56.6\%) from lower socio-economic strata scored $\geq 60 \%$ compared to the higher SES students. 
Table 2 Frequency distribution of behavioral risk factors of the Advanced level students

\begin{tabular}{|c|c|c|c|c|}
\hline \multirow[t]{2}{*}{ No. } & \multirow[t]{2}{*}{ Variable } & \multicolumn{3}{|c|}{ Frequency (\%) } \\
\hline & & Males & Females & Total \\
\hline \multirow[t]{3}{*}{1.} & \multicolumn{4}{|l|}{ Physical activity $(N=634)$} \\
\hline & Yes & $208(72.5 \%)$ & 198(57.1\%) & $406(64.0 \%)$ \\
\hline & No & $79(27.5 \%)$ & $149(42.9 \%)$ & $228(36.0 \%)$ \\
\hline \multirow[t]{3}{*}{2.} & \multicolumn{4}{|c|}{ Physical activity: adequacy among those who engaged in it $(N=406)$} \\
\hline & Adequate & $79(38.0 \%)$ & $50(25.3 \%)$ & $129(31.8 \%)$ \\
\hline & Inadequate & $129(62.0 \%)$ & $148(74.7 \%)$ & $277(68.2 \%)$ \\
\hline \multirow[t]{6}{*}{3.} & \multicolumn{4}{|c|}{ Type of physical activity $(N=421)^{a}$} \\
\hline & Sports & $148(71.1 \%)$ & $78(39.4 \%)$ & $226(55.7 \%)$ \\
\hline & Aerobics & $24(11.5 \%)$ & $12(6.1 \%)$ & $36(8.9 \%)$ \\
\hline & Yoga & $30(14.4 \%)$ & $32(16.2 \%)$ & $62(15.3 \%)$ \\
\hline & Dancing & $11(5.2 \%)$ & $80(40.4 \%)$ & $91(22.4 \%)$ \\
\hline & Gardening, housekeeping & $2(0.9 \%)$ & $4(2.0 \%)$ & $6(1.5 \%)$ \\
\hline \multirow[t]{3}{*}{4.} & \multicolumn{4}{|l|}{ Dietary habits $(N=634)$} \\
\hline & Unhealthy dietary habits & $193(67.2 \%)$ & $166(47.8 \%)$ & $359(56.6 \%$ \\
\hline & Healthy dietary habits & $94(32.8 \%)$ & $181(52.2 \%)$ & $275(43.4 \%$ \\
\hline \multirow[t]{4}{*}{5.} & \multicolumn{4}{|l|}{ Smoking $(N=652)^{b}$} \\
\hline & Ever users & $43(15.0 \%)$ & $2(0.6 \%)$ & $45(7.1 \%)$ \\
\hline & Current users & $18(6.3 \%)$ & $0(0.0 \%)$ & $18(2.8 \%)$ \\
\hline & Never users & $244(85.0 \%)$ & 345(99.4\%) & $589(92.9 \%)$ \\
\hline \multirow[t]{4}{*}{6.} & \multicolumn{4}{|c|}{ Alcohol consumption $(N=707)^{c}$} \\
\hline & Ever users & $89(25.6 \%)$ & $24(6.7 \%)$ & $113(16.0 \%)$ \\
\hline & Current users & $61(17.5 \%)$ & $12(3.3 \%)$ & $73(10.3 \%)$ \\
\hline & Never users & $198(56.9 \%)$ & $323(90.0)$ & $521(73.7 \%)$ \\
\hline \multirow[t]{7}{*}{7.} & \multicolumn{4}{|c|}{ Type of alcohol consumed by current users $(n=127)^{d}$} \\
\hline & Beer & $44(72.1 \%)$ & $12(100 \%)$ & $56(76.7 \%)$ \\
\hline & Arrack & $21(34.4 \%)$ & $0(0.0 \%)$ & $21(28.8 \%)$ \\
\hline & Brandy & $10(16.4 \%)$ & $1(8.3 \%)$ & $11(15.1 \%)$ \\
\hline & Jin & $14(22.9 \%)$ & $0(0.0 \%)$ & $14(19.2 \%)$ \\
\hline & Wine & $10(16.4 \%)$ & $5(41.7 \%)$ & $15(20.5 \%)$ \\
\hline & Whisky & 10(16.4\%) & $0(0.0 \%)$ & $10(13.7 \%)$ \\
\hline \multirow[t]{3}{*}{8.} & \multicolumn{4}{|l|}{ Obesity/Over weight $(N=634)$} \\
\hline & Obese/ Over weight & $43(15.0 \%)$ & $28(8.1 \%)$ & $71(11.1 \%)$ \\
\hline & Normal/Under-weight & $244(85.0 \%)$ & 319(91.9\%) & 563 (88.9\%) \\
\hline
\end{tabular}

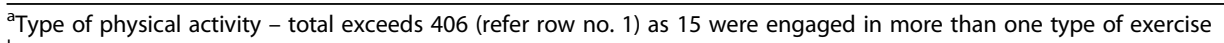

bSmoking - Total exceeds 634 as 18 current users were included under "ever users"

"Alcohol consumption - Total exceeds 634 as 73 current users were included under "ever users"

${ }^{\mathrm{d}}$ Type of alcohol consumed by current users - total exceeds 73 (refer row no. 7) as 54 consumed more than one type of alcohol

Overall better knowledge was significantly associated with race, father's education level $(p<0.1)$ and the stream of study $\mathrm{p}(0.001)$.

\section{Associated factors}

Based on the multivariate analysis, a good overall knowledge on NCDs was associated with being a science stream student $(\mathrm{OR}=3.3$; 95\%CI: 2.1-5.2) [Table 4].
A healthy diet (Model1) was significantly associated with female sex $(\mathrm{OR}=2.1 ; 95 \% \mathrm{CI}: 1.5-3.0)$ only [Table 5 ] . Adequate physical activity (Model 2) was associated with male sex $(\mathrm{OR}=2.1 ; 95 \%$ CI:1.4-3.2), non-science study streams $(\mathrm{OR}=2.1 ; 95 \% \mathrm{CI}: 1.2-3.7)$ and upper social SES $(\mathrm{OR}=2.0 ; 95 \% \mathrm{CI}: 1.3-3.0)$ [Table 5]. Abstinence from smoking (Model 3) was associated with female sex $(\mathrm{OR}=0$; 95\% CI: 1.5-infinity) and having good overall knowledge 
Table 3 Distribution of knowledge scores on selected Non Communicable Diseases

\begin{tabular}{|c|c|c|c|c|}
\hline Score on knowledge & $\begin{array}{l}\text { Frequency (\%) } \\
N=634\end{array}$ & Median & Mode & Mean (SD) \\
\hline \multicolumn{5}{|c|}{ Non-Communicable Diseases: Total Score $=11$} \\
\hline$<60 \%$ & $372(58.7 \%)$ & \multirow[t]{2}{*}{5} & \multirow[t]{2}{*}{9} & \multirow{2}{*}{$\begin{array}{r}5.5 \\
(3.3)\end{array}$} \\
\hline$\geq 60 \%$ & $262(41.3 \%)$ & & & \\
\hline \multicolumn{5}{|c|}{ Diabetes mellitus: Total Score $=31$} \\
\hline$<60 \%$ & $420(66.2 \%)$ & \multirow[t]{2}{*}{16.5} & \multirow[t]{2}{*}{18} & \multirow{2}{*}{$\begin{array}{l}16.0 \\
(5.2)\end{array}$} \\
\hline$\geq 60 \%$ & $214(33.8 \%)$ & & & \\
\hline \multicolumn{5}{|c|}{ Hypertension: Total Score $=24$} \\
\hline$<60 \%$ & $516(81.4 \%)$ & \multirow[t]{2}{*}{10} & \multirow[t]{2}{*}{9} & \multirow{2}{*}{$\begin{array}{l}10.4 \\
(4.5)\end{array}$} \\
\hline$\geq 60 \%$ & $118(18.6 \%)$ & & & \\
\hline \multicolumn{5}{|c|}{ Coronary artery disease: Total Score $=23$} \\
\hline$<60 \%$ & $277(43.7 \%)$ & \multirow[t]{2}{*}{14} & \multirow[t]{2}{*}{15} & \multirow{2}{*}{$\begin{array}{c}13.4 \\
(4.7)\end{array}$} \\
\hline$\geq 60 \%$ & $357(56.3 \%)$ & & & \\
\hline \multicolumn{5}{|l|}{ Stroke: Total Score $=23$} \\
\hline$<60 \%$ & $418(65.9 \%)$ & \multirow[t]{2}{*}{11} & \multirow[t]{2}{*}{14} & \multirow{2}{*}{$\begin{array}{l}11.3 \\
(6.6)\end{array}$} \\
\hline$\geq 60 \%$ & $216(34.1 \%)$ & & & \\
\hline \multicolumn{5}{|c|}{ Cancers: Total Score $=34$} \\
\hline$<60 \%$ & $391(61.7 \%)$ & \multirow[t]{2}{*}{19} & \multirow[t]{2}{*}{21} & \multirow{2}{*}{$\begin{array}{c}18.2 \\
(6.0)\end{array}$} \\
\hline$\geq 60 \%$ & $243(38.3 \%)$ & & & \\
\hline \multicolumn{5}{|l|}{ Diet: Total Score $=37$} \\
\hline$<60 \%$ & $159(25.1 \%)$ & \multirow[t]{2}{*}{27} & \multirow[t]{2}{*}{31} & \multirow{2}{*}{$\begin{array}{c}25.9 \\
(6.6)\end{array}$} \\
\hline$\geq 60 \%$ & $475(74.9 \%)$ & & & \\
\hline \multicolumn{5}{|c|}{ Physical activity: Total Score $=11$} \\
\hline$<60 \%$ & $275(43.4 \%)$ & \multirow[t]{2}{*}{7} & 10 & 6.8 \\
\hline$\geq 60 \%$ & $359(56.6 \%)$ & & & \\
\hline Smoking: Total Score $=$ & 10 & & & \\
\hline$<60 \%$ & $324(51.1 \%)$ & 5 & 5 & 5.4 \\
\hline$\geq 60 \%$ & $310(48.9 \%)$ & & & (1.8) \\
\hline Alcohol Consumption: & Total Score $=12$ & & & \\
\hline$<60 \%$ & $371(58.5 \%)$ & 7 & 7 & 6.9 \\
\hline$\geq 60 \%$ & $263(41.5 \%)$ & & & (3.2) \\
\hline Overall: Total Score $=$ & & & & \\
\hline$<60 \%$ & $362(57.1 \%)$ & 124 & 139 & 119.7 \\
\hline$\geq 60 \%$ & $272(42.9 \%)$ & & & $(31.0)$ \\
\hline
\end{tabular}

Table 4 Factors significantly associated with knowledge

\begin{tabular}{llll}
\hline Model & $\begin{array}{l}\text { Unadjusted } \\
(95 \% \mathrm{Cl})\end{array}$ & $\begin{array}{l}\text { Adjusted }{ }^{\text {a }} \\
(95 \% \mathrm{Cl})\end{array}$ \\
\hline $\begin{array}{l}\text { Knowledge - Overall Score } \geq 60 \% \\
\text { Science stream }\end{array} \quad 3.2$ & $2.1-4.8$ & 3.3 & $2.1-5.2$ \\
\hline $\begin{array}{l}\text { a adjusted for Sex, stream of study, Fathers education level, } \\
\text { level, Socio-economic status }\end{array}$
\end{tabular}

Table 5 Factors significantly associated with Practices

\begin{tabular}{|c|c|c|c|c|}
\hline Model & \multicolumn{2}{|c|}{$\begin{array}{l}\text { Unadjusted } \\
(95 \% \mathrm{Cl})\end{array}$} & \multicolumn{2}{|c|}{$\begin{array}{l}\text { Adjusted }{ }^{\mathrm{b}} \\
(95 \% \mathrm{Cl})\end{array}$} \\
\hline \multicolumn{5}{|l|}{ Model 1-Healthy Diet } \\
\hline Female & 3.2 & $2.1-4.8$ & 3.3 & $2.1-5.2$ \\
\hline \multicolumn{5}{|c|}{ Model 2-Adequate Physical Activity } \\
\hline Male & 2.3 & $1.5-3.6$ & 2.1 & $1.4-3.2$ \\
\hline Non-Science & 1.6 & $0.9-2.8$ & 2.1 & $1.2-3.7$ \\
\hline Upper SES & 2.0 & $1.3-3.0$ & 2.0 & $1.3-3.0$ \\
\hline \multicolumn{5}{|c|}{ Model 3- Abstinence from Smoking } \\
\hline Females & 0 & 5.6-Infinity & 0 & 1.5-Infinity \\
\hline Good overall knowledge & 2.1 & $0.8-5.6$ & 4.1 & $1.2-13.7$ \\
\hline \multicolumn{5}{|c|}{ Model 4- Abstinence from Consumption of Alcohol } \\
\hline Females & 3.9 & $3.9-15.7$ & 6.9 & $3.4-13.9$ \\
\hline $\begin{array}{l}\text { Mothers' education } \\
>\text { GCE }(\mathrm{O} / \mathrm{L})^{\mathrm{a}}\end{array}$ & 1.1 & $0.6-2.0$ & 2.9 & $1.1-8.4$ \\
\hline $\begin{array}{l}\text { Father's education } \\
>\text { GCE }(\mathrm{O} / \mathrm{L})\end{array}$ & 1.9 & $0.9-3.9$ & 3.5 & $1.1-11.2$ \\
\hline
\end{tabular}

on NCDs (OR $=4.1 ; 95 \%$ CI:1.2-13.7). Abstinence from alcohol (Model 4) was associated with female sex $(\mathrm{OR}=6.9$; 95\% CI:3.4-13.9), and mother and fathers' educational level greater than GCE O/L $(\mathrm{OR}=2.9 ; 95 \%$ CI:1.1-8.4 and OR $=3.5 ; 95 \%$ CI:1.1-11.2 respectively) [Table 5].

\section{Discussion}

Results of the present study indicate that the overall knowledge (42.9\%; 95\% CI: 39.0-46.9\%) on NCDs and lifestyle-practices among the study group was poor. Despite the above, a higher proportion (56.2\%) of students had good knowledge on coronary artery disease, healthy diet (74.9\%) and physical activity (56.6\%) as protective factors. In comparison to knowledge, the proportion practicing overall adequate physical activity was only $20.3 \%(n=129)$. However previous studies have reported that awareness of PA recommendations and the actual level of PA are significantly associated. $[17,18]$ There is consensus in the literature that physical activity declines markedly during adolescence. [19] This might explain the current finding that irrespective of the awareness the proportion involved in adequate PA is low.

The overall knowledge of diabetes hypertension and other NCDs were poor among students. The poor knowledge might be dangerous because these are the individuals who are about to enter the society and to fight the epidemic of NCDs, and should be knowledgeable enough of the diseases and their prevention. The good knowledge of coronary artery disease might be from family members whose suffering from the disease and a 
good knowledge on diet, and physical activity would be due to the high level of publicity given to them to promote these.

Overall good knowledge about NCDs was higher among science stream students. Although kept to a minimum, it is possible the use of technical terms may have been factor contributing to the poor knowledge demonstrated among non-science stream students. This highlights the importance of addressing such deficiencies during the preparation of health education materials, in order to ensure messages reach all equally. Given the poor knowledge observed among the students of the highest school grade, the need for quick action becomes evident.

Less than one-third of students reported consuming adequate quantities of vegetables/green leaves (32\%) and fruits (24\%). This finding is comparable with the results reported by Vithana, [20] in a study conducted among teachers in Kegalle Medical Officer of Health area, Sri Lanka. The best strategy to encourage adoption of a healthy diet appears to be through a school-based policy, combined with awareness programs and participatory approach of both students and the community. [7, 21] However, a majority of students (73.3\%) consumed a home-prepared breakfast, the finding of which is also consistent with the study reported by Kumarapeli. [22] Individual practices related to diet may be dependent on family food choices as well as availability, accessibility, and affordability which are influenced by the fluctuations in cost due to weather conditions experienced throughout the year.

Various cutoffs for adequate physical activity levels among adolescents have been used in previous studies. [23] The current application of adult physical activity guidelines for adolescents makes it difficult to accurately categorise physical activity levels among them. [24] The current study considered adequate physical activity levels as fulfilling both a time duration of $\geq 60 \mathrm{~min}$, on a daily basis [13, 25], Based on this cutoff, physical activity was inadequate among a majority of the students, contrary to previous studies. [26-28] One reason for the observed low prevalence could be the different definitions used to quantify "adequate activity." Another reason may be due to preparation for the GCE A/L examination, which the Year 13 students were due to sit soon after data collection for this study was undertaken. This exam is highly competitive and thus require them to attend extra classes after school hours, depriving them of additional time for other activities. Both this and a lack of conducive environments could be contributory factors for the inadequacy of overall physical activity. Upper socioeconomic status, male sex, and non-science study streams were the factors associated with an adequate physical activity. The observed gender difference in adequate physical activity was also reported by Singh et al. in New Delhi India. [29] The association with higher socioeconomic status may be attributed to the ability to pay for the use of gymnasiums, combined with the parental use of the same services. [30] Contrasting with the poor knowledge levels among non-science stream students, a significantly higher proportion of these students were engaged in an adequate amount of physical activity.

The low lifetime prevalence of smoking observed among both sexes is consistent with other studies conducted among adolescents in Sri Lanka. [6, 31] However, Katulanda et al. [32] has previously reported a higher prevalence of lifetime smoking in male and female students, of $27 \%$ and $13.3 \%$ respectively. This higher prevalence may be due to the difference in study settings, as Katulanda et al. [32] conducted the study among students representing the whole of Colombo District, which includes the capital city of Colombo. Maharagama education division, which is situated away from the capital city of Colombo could be considered a semi-urban area, in which the lifestyles of students are less modernized. Likelihood of abstinence from smoking was significant $(p<0.001)$ infinite (certain) among females, which is encouraging to note, given the current trend of the tobacco industry to target more females than males. Another factor that protected adolescents from smoking was having a good knowledge about NCDs. This finding is important from a policy perspective, in that, given the knowledge, the students are more likely to refrain from harmful behaviors. Similar to other studies conducted in Sri Lanka, socio-demographic characteristics did not demonstrate any association with smoking. [31, 33].

The prevalence of those who were current alcohol consumers in the present study was low (11.5\%). Similar trends are also observed among teenagers of other Asian countries. [34] In the western countries a higher prevalence among adolescents in comparison to adults is often observed. [34] According to the present study, abstinence from alcohol was significantly higher among female students when their father and/or mother were educated above GCE O/L. The low rates for female drinkers reflect the national trend, where very few females resort to drinking. [35] However, socio-economic status was not observed to be associated with the prevalence of drinking in this study. This fact may also be attributed to the semi-urban nature of the setting. When the parents are better educated, they also guide the children to become more educated and adopt healthy lifestyles and behaviors. However, when parents themselves are less educated, their capacity to advise children is lower, and the children themselves are likely to overrule them.

Concerning smoking and alcohol intake, the social desirability bias was kept to a minimum by making the 
questionnaires anonymous. As the majority of the respondents were Buddhist, providing information especially on alcohol intake is likely to have been largely distorted, in the absence of anonymity. Its noteworthy that risk behaviours cluster in adolescence, meaning that smokers are more likely to consume alcohol and resort to unhealthy behaviours. Hence; its important that the above are considered when designing programmes. [36, 37].

In the present study, $15 \%(n=43)$ of males and $8.1 \%$ $(n=28)$ of females were either overweight or obese. The current findings showed a higher prevalence of overweight/obesity compared to a study conducted in the Southern province of Sri Lanka, which reported a prevalence of $4 \%$. [6] This difference could be attributed to the regional differences, and the different cut-off values used to identify overweight and obesity. In the Perera et al. [6] study students whom were $\geq 25 \mathrm{~kg} / \mathrm{m}^{-2}$, were considered as overweight or obese, whereas in the present study BMI for age was considered. A significantly higher proportion of females than males had a BMI of less than $25 \mathrm{Kgm}^{-2}$. It could be because males have a desire for a heavier physique and muscularity in contrast to females who desire to be thin. [36].

To the best of our knowledge, the current study was the first to determine the level of knowledge on selected NCDs and their associated preventive practices among adolescents in Sri Lanka. As the study was confined to year 13 students of nine schools (consisting of only $41 \%$ of all schools in the educational zone), the study findings are generalizable to these schools of Maharagama Education division. However, schools of Maharagama Education division do not differ much from schools of the other educational divisions in Sri Lanka. Further, the confounders considered for the multivariate analysis were confined to factors gathered from students and might have reporting bias; although all possible measures were taken to minimize the reporting bias. Also as with any other study, the potential of unmeasured and residual confounding factors could be a limitation of the study.

As the study participants were students, information related to availability, accessibility, affordability and diversity of diet was not collected, which may have led to the potential for unmeasured or residual confounding. All above are considered as limitations of the study.

\section{Conclusion and Recommendations}

The knowledge and lifestyle practices of adolescent students with regard to NCD's and their primary prevention were found to be unsatisfactory. This highlights the importance of establishing a system for NCD risk factor surveillance, and implementing awareness raising programs among this group. Conducting regular Global School Health Survey (GSHS) in Sri Lanka is one key recommendation. GSHS is a school-based survey conducted primarily among students aged 13-17 years. Measures should also be taken to incorporate healthy lifestyle education as a major component of the school curriculum, with an aim to provide knowledge as well as a conducive environment for the practice of the same. The strategy for this should include establishment of health promoting schools through school health clubs, with a healthy canteen policy, which is strictly adhered to. The fact that children are considered the best change agents to disseminate knowledge and practice to the family and the community should be maximally explored, as this may prove advantageous for both adolescents and adults equally. [7, 21] However, quick action is imperative if the above objective is to be achieved through children, in order to control the rising epidemic of NCDs.

\section{Additional files}

Additional file 1: The Self Administered Questionnaire to assess Knowledge of non-communicable diseases and practices related to healthy lifestyles among adoloscents. (PDF 7388 kb)

Additional file 2: Table S1. Assignment of score for the component on knowledge. (DOCX $14 \mathrm{~kb}$ )

\section{Abbreviations}

BMI: Body mass index; GCE A/L: General Certificate of Education; AdvancedLevel; NCDs: Non-communicable diseases; SES: Socio-economic status; WHO: World Health Organization

\section{Acknowledgements}

The authors gratefully acknowledge the time and effort given by all the schools and participants to make this study a success.

\section{Funding}

Funding for this study was provided by the Education, Training \& Research Unit Ministry of Health, Sri Lanka.

\section{Availability of data and materials}

All data sets are available for researcher eligible for access upon request to the corresponding author (anujigamage@gmail.com).

\section{Authors' contributions}

AUG and PJ designed the analysis plan. PJ supervised the project. AUG performed the statistical analyses and wrote the first draft of the manuscript. All authors contributed to the interpretation of the results and the revision of the manuscript. PJ is the guarantor. Both authors read and approved the final manuscript.

Ethics approval and consent to participate Informed written consent was obtained from the parents/guardians by sending the necessary forms, one day before the survey and assent from the students immediately before recruitment. Ethical clearance for the study was obtained (P31/06/2009) from the Ethical Review Committee of the Faculty of Medicine, University of Kelaniya, Sri Lanka.

Consent for publication

Not Applicable.

\section{Competing interests}

The funding agency had no role in the design, analysis, or interpretation of data; writing of the report; or the decision to submit the article for publication. The authors were fully independent of the funding agency in 
conducting the research. The authors declare that they have no conflicts of interest. All authors have access to the data analyzed in the study and take responsibility for the integrity of the data and accuracy of the analysis.

\section{Publisher's Note}

Springer Nature remains neutral with regard to jurisdictional claims in published maps and institutional affiliations.

\section{Author details}

${ }^{1}$ Consultant Community Physician, Ministry of Health, 385, Ven. Baddegama Wimalawansa Thero Mawatha, Colombo 10, Sri Lanka. ${ }^{2}$ Professor in Public Health, Department of Public Health, Faculty of Medicine, University of Kelaniya, Ragama, Sri Lanka.

Received: 21 December 2016 Accepted: 21 July 2017

Published online: 26 July 2017

\section{References}

1. Lungsiwa PT: Urbanization and lifestyle changes related to noncommunicable diseases: An exploration of experiences of urban residents who have relocated from the rural area to Khayelitsha, an urban township in Cape Town.: University of the Western Cape . 2007.

2. Siegel KR, Patel SA, Ali MK. Non-communicable diseases in South Asia: contemporary perspectives. Br Med Bull. 2014;111(1):31-44.

3. Rannan-Eliya CA RP, Brearley L, Elwalagedara R, Abeykoon ATPL, Balasundaram A, Dalpatadu S. An Assessment of the Burden, Issues and Policy Options in Curative Care Services Delivery and Non- communicable Diseases in Sri Lanka. Sri Lanka: Institute for Health Policy Colombo; 2010.

4. WHO: Adolescent Health. In: Health topics Edited by WHO, vol. 2010. WHO; 2004.

5. Thalagala NIRL. National survey on emerging issues among adolescents in Sri Lanka. Colombo: UNICEF; 2004

6. Perera B, Ostbye T, Fernando N, Abeygunawardena V, Ariyananda PL, Woods C. Health and. Health behavior among late adolescentsin Southern Sri Lanka. Galle Medical Journal. 2007:12(1):14-20.

7. Bartlett EE. The contribution of school health education to community health promotion: what can we reasonably expect? Am J Public Health 1981;71(12):1384-91

8. Sri Lanka Education Information - 2010 [http://www.moe.gov.lk/english/ index.php?option=com_content\&view=article\&id=1220\&ltemid $=922]$.

9. Lwanga SK, Lemeshow S: Sample size determination in health studies: a practical manual. 1991

10. PAHO. Health in the Americas. In: Scientific Publication No 569 Washington, D.C: Pan American Health Organization; 1998.

11. WHO. The WHO STEPwise approach to Surveillance of non- communicable diseases (STEPS). Geneva: Non-communicable Diseases and Mental Health; 2003.

12. Thalagala N. An Index to measure socio economic status: Asset approach. Journal of College of Community Physicians of Sri Lanka. 2004;9:32-9.

13. WHO. Global recommendations on physical activity for health. Geneva: Switzerland WHO press; 2010.

14. Md O, Onyango AW, Borghi E, Siyam A, Nishida C, Siekmann J. Development of a WHO growth reference for school-aged children and adolescents. Bull World Health Organ. 2007;85(9):660-7.

15. WHO: Simplified field tables- BMl for age boys/ girls 5 to 19 years (percentiles) In. Edited by WHO. Geneva.; 2007.

16. SPSS Inc. Released 2007. SPSS for Windows VC, SPSS Inc.

17. Cameron C, Craig CL, Bull FC, Bauman A. Canada's physical activity guides: has their release had an impact? Canadian journal of public health $=$ Revue canadienne de sante publique. 2007;98(Suppl 2):S161-9.

18. Plotnikoff RC, Lippke S, Johnson ST, Hugo K, Rodgers W, Spence JC. Awareness of Canada's Physical Activity Guide to Healthy Active Living in a large community sample. American journal of health promotion : AJHP. 2011:25(5):294-7.

19. Allison KR, Adlaf EM, Dwyer JJ, Lysy DC, Irving HM. The decline in physical activity among adolescent students: a cross-national comparison. Canadian Journal of Public Health/Revue Canadienne de Sante'e Publique. 2007:97-100.

20. Vithana PVS. Selected life style related Risk factors among teachers in Kegalle MOH area. Colombo: University of Colombo; 2003.
21. WHO. School Policy Framework: Implementation of the WHO Global Strategy on Diet, Physical Activity and Health. Geneva: World Health Organization; 2008.

22. Kumarapeli VAT. A comparison of the dietary pattern of adolescent school girls in two defined urban and rural settings. Journal of Community Physicians of Sri Lank. 2004;9:13-8.

23. Morrow JR Jr, Tucker JS, Jackson AW, Martin SB, Greenleaf CA, Petrie TA Meeting physical activity guidelines and health-related fitness in youth. Am J Prev Med. 2013;44(5):439-44.

24. Lowry R, Galuska DA, Fulton JE, Wechsler H, Kann L, Collins JL. Physical activity, food choice, and weight management goals and practices among U.S. college students. American Journal of Preventive Medicine. 18(1):18-27.

25. WHO. Preventing Chronic Diseases: A Vital Investment. Geneva: WHO; 2005

26. Katzmarzyk PT, Ardern C. Physical activity levels of Canadian children and youth: current issues and recommendations. Can J Diabetes. 2004;28:67-78.

27. Lee E-Y, Carson V, Jeon JY, Spence JC. Prevalence of Physical Activity and Sitting Time Among South Korean Adolescents. Asia Pac J Public Health. 2016;28(6):498-506.

28. Li M, Dibley MJ, Sibbritt DW, Zhou X, Yan H. Physical activity and sedentary behavior in adolescents in Xi'an City China. J Adolesc Health. 2007;41(1):99101.

29. Singh AK, Maheshwari A, Sharma N, Anand K. Lifestyle associated risk factors in adolescents. The Indian Journal of Pediatrics. 2006;73(10):901-6.

30. Kantomaa MT, Tammelin TH, Näyhä S, Taanila AM. Adolescents' physical activity in relation to family income and parents' education. Prev Med. 2007; 44(5):410-5.

31. Ismail AC, SDAR. Prevalence and patterns of substance use among secondary school students in the Colombo District. Journal of Community Physicians of Sri Lanka. 2008;13(2):17-25.

32. Katulanda P, Liyanage IK, Wickramasinghe K, Piyadigama I, Karunathilake IM, Palmer PH, Matthews DR. Tobacco smoking among school children in Colombo district, Sri Lanka. Asia-Pacific journal of public health / Asia-Pacific Academic Consortium for Public Health. 2015:27(2):Np278-87.

33. Karunapema RPP. Prevalence of selected health risk behaviors and associated factors, among G.C.E. Ordinary level student in $\mathrm{MOH}$ Dampe. Colombo: University of Colombo; 2004.

34. WHO. Alcohol, gender and drinking problem - perspectives from low and middle income countries. Geneva Switzerland: Department of Mental Health and Substance; 2005

35. Almeida-Filho N, Lessa I, Magalhães L, Araújo MJ, Aquino E, Kawachi I, James SA. Alcohol drinking patterns by gender, ethnicity, and social class in Bahia Brazil. Revista de Saúde Pública. 2004:38(1):45-54

36. Sakamaki R, Toyama K, Amamoto R, Liu C-J, Shinfuku N. Nutritional knowledge, food habits and health attitude of Chinese university students a cross sectional study. Nutr J. 2005;4:4-4.

37. Burke V, Milligan R, Beilin L, Dunbar D, Spencer M, Balde E, Gracey M. Clustering of health-related behaviors among 18-year-old Australians. Prev Med. 1997:26(5):724-33.

\section{Submit your next manuscript to BioMed Central and we will help you at every step:}

- We accept pre-submission inquiries

- Our selector tool helps you to find the most relevant journal

- We provide round the clock customer support

- Convenient online submission

- Thorough peer review

- Inclusion in PubMed and all major indexing services

- Maximum visibility for your research

Submit your manuscript at www.biomedcentral.com/submit 